\title{
Punctiform and polychromatic pre-Descemet's dominant corneal dystrophy
}

\author{
DAVID FERNANDEZ-SASSO, JORGE E. P. ACOSTA, AND ENRIQUE MALBRAN \\ From the Centro Oftalmologico Malbran, Buenos Aires, Argentina
}

SUMMARY A new type of pre-Descemet's corneal dystrophy is described. The opacities are punctiform, polychromatic, of uniform size, and evenly distributed over the whole cornea. The diagnosis is made only by slit lamp because there is no visual impairment. The disease is hereditary and follows the autosomal mode of inheritance with a high percentage of penetrance, expressivity, and specificity in 4 successive generations, in which 8 affected members were observed among a total of 46 .

The purpose of this paper is to present a clinical form of corneal dystrophy with pre-Descemet's localisation, familial character, and dominant heredity. We observed first this corneal dystrophy in a routine test on a woman aged 36 who presented with slight myopia. The deep polychromatic opacities seen by the slit lamp called it to our attention. We were then able to examine 46 members of her family and found the same corneal feature in 8 of them. Without exception this corneal dystrophy did not interfere with visual acuity. Because of its clinical and biomicroscopical characteristics and its localisation we include it in the group of the socalled pre-Descemet's corneal dystrophies, classified topographically by François (1966).

After reviewing the literature on the corneal pathology we considered our cases showed a special type of dystrophy that had not been reported previously. There was no backward indentation on Descemet's membrane nor endothelial abnormalities (Thomsitt and Bron, 1975) so far as we could judge from slit-lamp examination. We showed Professor Jules François one of these cases, and he agreed that it represented a unique clinical form and was the more interesting because of its hereditary character.

Vogt (1923) was the first to describe a preDescemet's dystrophy, which he called cornea farinata. In this paper we refer only to pre-Descemet's dystrophies. Paufique and Etienne (1950) reported a family trait in the senile and presenile forms. Maeder and Danis (1947) described a deep filiform dystrophy of the cornea associated with keratoconus. Later, Franceschetti et al. (1957) demonstrated that

Address for reprints: Dr David Fernandez-Sasso, Avenida de Mayo 1437, Buenos Aires, Argentina this dystrophy is not necessarily associated with keratoconus. Franceschetti and Maeder (1954) described a case of deep punctiform dystrophy associated with ichthyosis. Then Franceschetti and Schlaeppi (1957) presented a case of pre-Descemet's dystrophy with ichthyosis and band-shaped degeneration.

Collier (1963) made a comparative study of all these cases, establishing an order and classifying them as pre-Descemet's dystrophies. It should be emphasised that neither the ichthyosis nor the keratoconus are necessary associations of these dystrophies. The same author rather vaguely indicates its familial and hereditary character.

Grayson and Wilbrandt (1967) proposed a new classification based on the shape of the opacities. Curran et al. (1974), in a histopathological study of a pre-Descemet's corneal dystrophy, found enlarged keratocytes with intracytoplasmatic vacuoles containing a lipofuscin-like lipoprotein. They considered this process to be related to age. Fiore and Regamey-Steiger (1975) described the association of a dominant autosomal ichthyosis and a corneal preDescemet's dystrophy of a deep punctiform type.

One of us (Malbran, 1972), studying the family of a typical case of macular dystrophy of Groenouw, found that a cousin of the propositus presented a preDescemet's dystrophy that was then classified as filiform and by its morphological characteristics and its distribution was similar to the one we are presenting in this report.

\section{Case report}

First generation. A couple from the French Pyrenees established themselves in Buenos Aires in the 19th century. Their descendants were: 
Fig. 1 Family tree showing the dominant autosomal heredity of the punctiform and polychromatic pre-Descemet's corneal dystrophy

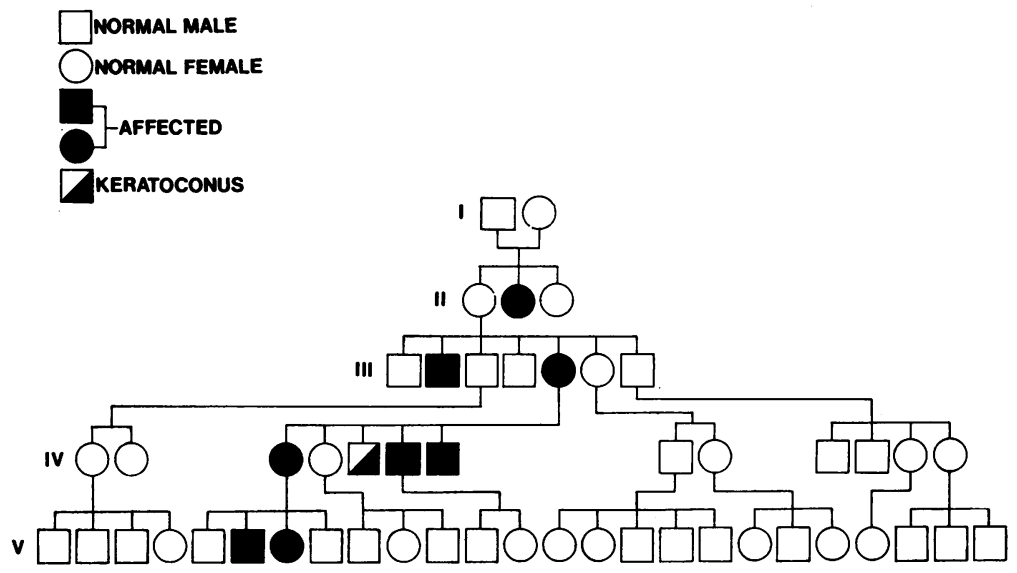

Second generation. Three daughters. One of these died without her descendants being examined. The second was single and had no offspring; she was examined when she was 87 years old, 2 weeks before her death. She suffered from the dystrophy reported here. The third sister married a native Argentian of Austro-Hungarian origin and is the mother of the third generation, consisting of 7 members.

Third generation. Five men and 2 women. They were all examined, and 2 of them showed the dystrophy. One, a single man of 68 , without descendants, did not present any other ocular disease. The other, a woman of 62 , married and had 5 children.

Fourth generation. Three men and 2 women. As in the third generation, all the 13 members were examined and the dystrophy was found in 3 of them. A fourth person, a man of 33, has keratoconus and is slightly myopic but suffers no dystrophy. Of the 3 who have the dystrophy 1 is a 31 -year-old single man with no descendants so far, slightly myopic. The second is a married man of 32 with a son and daughter. The children have no dystrophy. The third is a woman of 36 , with 4 children.

Fifth generation. All 25 members of this generation have been examined, and only 2 of them present-the dystrophy. One is a boy of 5 years and the other a girl of 3.

In the course of this research we have seen all the living members of this family. In all, 46 people were examined. At present all members of the third and fourth generations are alive.

\section{Discussion}

A comparison of previous reports of pre-Descemet's dystrophies with the study we are now presenting shows the following differences.

Cornea farinata. Greyish, punctiform, and very thin elements and wavy lines with the form of a coma. Invisible to indirect illumination.. Distributed throughout the cornea except at the periphery.

Deep filiform dystrophy. Filaments in curls and sometimes punctiform. They are white to direct illumination and bluish grey to indirect illumination. Generally of central location and sometimes paracentral.

Deep punctiform dystrophy. Punctiform elements that are present in small groups of filaments, some of which are of a dendritic type, and others like canes or comas. Bluish white colour. Visible to direct and indirect illumination. Ring or strictly axial distribution of the opacities.

Polychromatic dystrophy. Thin punctiform elements that show different colours. Visible to direct and indirect illumination. Distributed all over the cornea up to the limbo without leaving free spaces.

All these dystrophies as well as the type we are presenting are similar in their essential features, but they differ completely in colour, since this dystrophy is the only one that presents a variety of colour that is constant in both types of illumination. Moreover, the distribution differs, because it is uniform throughout the whole cornea.

Another distinct slit-lamp feature of this dystrophy is the presence of some polychromatic opacities leaving empty, clear spaces larger than the opacities themselves. These opacities are punctiform and have polychromatic reflections, some are yellow, others are greenish, and others are red. Their size is more or less uniform, as is their topographical distribution, which covers the whole corneal diameter at the pre-Descemet's depth. There is a slight decrease in number at the extreme periphery, and they are not aggregated in any particular formations.

This entity can be seen only with the slit lamp with direct and indirect illumination. We would 
emphasise that the opacities are of equal size, being larger than those of the farinata. The dystrophy entity can be diagnosed only with the slit lamp. It does not evolve with time, nor does it change with the patient's age.

From studying the family tree we deduce that the pre-Descemet's dystrophy in this case is hereditary. The disease has been transmitted as an autosomal dominant way. This type of heredity is designated because the disease was present in 4 successive generations, about $50 \%$ of affected members having the trait without sex predilection.

Other characteristics of hereditary diseases are present: homochronicity, that is, the appearance of the illness at the same age among different members, and homology and homotypy, that is, the repetition of the illness and the same symptoms in the different members of the same family group.

The gene appears to show a high degree of penetrance, with similar phenotypic expression in different members of the family. Moreover, this corneal disease shows besides its familial character other typical signs that permit its identification as corneal dystrophy. These are bilaterality and symmetry, absence of neovascularisation, congenital or early onset, and no evolution.

The clinical and biomicroscopical aspect of our cases leads us to regard it as a new dystrophy. Nevertheless, we must point out its relation to other pre-Descemet's dystrophies.

\section{References}

Collier, M. (1963). Les dystrophies prédescemetiques (à propos d'un cas de cornea farinata). Bulletin des Sociétés d'Ophtalmologie, 1, 53-63.
Collier, M. (1964). Caractere hérédo-familial de la dystrophie ponctiforme prédescemetique. Bulletin des Sociétés d'Ophtalmologie, 9, 731-734.

Curran, E., Kenyon, K., and Green, W. R. (1974). PreDescemet's membrane corneal dystrophy. American Journal of Ophthalmology, 77, 711-716.

Fiore, C., and Regamey-Steiger, E. (1975). Dystrophie prédescemetique de la cornée dans un cas d'ichtyose congénitale. Archives d'Ophtalmologie, 35, 961-964.

Franceschetti, A., and Maeder, G. (1954). Dystrophie profonde de la cornée dans un cas d'ichtyose congénitale. Bulletin et Mémoires, Société Française d'Ophtalmologie, 67, 146-149.

Franceschetti, A., Chodos, J., Dieterle, P., and Forni, S. (1957). Severe filiforme dystrophy of the cornea. Bulletin et Mémoires, Société Française d'Ophtalmologie, 70, 175179.

Franceschetti, A., and Schlaeppi, V. (1957). Bandlike degeneration and pre-Descemet dystrophy of the cornea in a case of congenital ichthyosis. Dermatologica, 115, 217-223.

François, J. (1966). Hérédo-familial corneal dystrophies. Transactions of the Ophthalmological Societies of the United Kingdom, 86, 367-416.

Grayson, M., and Wilbrandt, M. (1967). Pre-Descemet dystrophy. American Journal of Ophthalmology, 64, 277282.

Maeder, G., and Danis, P. (1947). Sur une nouvelle forme de dystrophie cornéene (dystrophia filiformis profunda corneae) associée à un kératocone. Ophthalmologica, 114, 246-248.

Malbran, E. (1972). Corneal dystrophies: a clinical, pathological and surgical approach. Transactions of the American Academy of Ophthalmology and Otolaryngology, 76, 573624.

Paufique, L., and Etienne, R. (1950). La cornea farinata. Bulletin des Sociétés d'Ophtalmologie, 6, 522-526.

Strachan, I. M., and Maclean, H. (1968). Posterior polymorphous dystrophy of the cornea. British Journal of Ophthalmology, 52, 270-272.

Thomsitt, J., and Bron, A. J. (1975). Polymorphic stromal dystrophy. British Journal of Ophthalmology, 59, 125-132.

Vogt, A. (1923). Cornea farinata. Schweizerische medizinische Wochewschrift, 53, 991. 